\title{
Regulamentações Ambientais e Competitividade: um estudo comparativo entre brasil e frança
}

\section{Environmental Regulations and Competitiveness: a} comparative study between brazil and france

\author{
Jaluza Maria Lima Silva Borsatto \\ Universidade Federal de Uberlândia (UFU) \\ email:jaluza.silva@ufu.br
}

\section{Camila Lima Bazani}

Universidade Federal de Uberlândia (UFU)

email:camilabazani@ufu.br

\section{RESUMO}

Este estudo objetivou verificar se existe algum tipo de associação entre o rigor das regulamentações ambientais e a competitividade dos países Brasil e França, entre 2005 e 2015, com base nos resultados dos indicadores de rigor das regulamentações ambientais (Environmental Policy Stringency Index, OECD) e competitividade (Global Competitiveness Index, WEF). Ademais, buscou-se analisar a evolução do rigor das regulamentações ambientais e da competitividade, e um comparativo quanto à associação entre o rigor das regulamentações ambientais e a competitividade desses países. Trata-se de uma pesquisa quali-quantitativa, analisando descritivamente as variáveis em estudo e utilizando-se do teste estatístico correlação linear de Pearson. Os resultados demonstraram que a França apresentou um rigor maior em suas políticas ambientais que o Brasil, e demonstrou um maior grau de competitividade. Além disso, as regulamentações ambientais no Brasil estavam correlacionadas negativamente somente com três pilares da competitividade, enquanto a França apresentou correlação com oito pilares da competitividade. $O$ trabalho contribui com a literatura demonstrando a importância do rigor das regulamentações ambientais para a melhoria no desempenho da produção industrial verde que promove o desenvolvimento econômico sustentável e melhora a competitividade a longo prazo tanto em economias emergentes como em economias desenvolvidas.

Palavras-Chave: Regulamentações Ambientais. Competitividade. Brasil. França.

\section{ABSTRACT}

This study aimed to verify if there is any kind of association between the rigor of environmental regulations and the competitiveness of the countries Brazil and France, between 2005 and 2015, based on the results of the environmental policy stringency indicators (Environmental Policy Stringency Index, OECD) and competitiveness (Global Competitiveness Index, WEF). In addition, we sought to analyze the evolution of the rigor of environmental regulations and competitiveness, and a comparison as to the association between the rigor of environmental regulations and the competitiveness of these countries. It is a qualitative and quantitative research, descriptively analyzing the variables under study and using Pearson's linear correlation statistical test. The results showed that France presented greater rigor in its environmental policies than Brazil and demonstrated a greater degree of competitiveness. In addition, environmental regulations in Brazil were negatively correlated with only three pillars of competitiveness, while France showed a correlation with eight pillars of competitiveness. The work contributes to the literature demonstrating the importance of strict environmental regulations for improving the performance of green industrial production that promotes sustainable economic development and improves long-term competitiveness in both emerging and developed economies.

Key-words: Environmental Regulations. Competitiveness. Brazil. France. 


\section{INTRODUÇÃO}

Com o advento da Revolução Industrial no século XVIII, a acelerada industrialização e o crescimento dos centros urbanos fizeram com que as questões relacionadas ao meio ambiente passassem a ter maior destaque na sociedade. Apesar disso, naquela época, os recursos naturais eram considerados inesgotáveis fontes de matéria-prima e não havia a consciência ambiental, conforme exposto por Costa e Marion (2007). Somente nas últimas décadas, com a intensificação do processo de globalização econômica e consequente escassez de recursos e degradação ambiental, é que a preservação do meio ambiente passou a ser um desafio para a humanidade.

Nesse cenário, os governos passaram a formular políticas para o enfrentamento dos problemas ambientais, sendo o primeiro marco histórico do desenvolvimento sustentável o Clube de Roma em 1968 quando foi publicado o estudo "The Limits to Growth”, passando pela Conferência da Organização das Nações Unidas sobre o Meio Ambiente Humano, em Estocolmo em 1972, pela Comissão Mundial sobre o Meio Ambiente e o Desenvolvimento o Relatório de Brundtland em 1987, pelo desenvolvimento da Agenda 21 na ECO-92 que ocorreu no Brasil em 1992, chegando na última década com a assinatura do Acordo de Paris adotado em 2015, com o objetivo de fortalecer a resposta global à ameaça das mudanças climáticas e onde foram definidos os Objetivos do Desenvolvimento Sustentável na Agenda 2030 (NAÇÕES UNIDAS, 2015).

Desse modo, gradativamente, a gestão ambiental passou a ter um importante papel para o desenvolvimento dos países que, permeados pelos desafios de um ambiente concorrencial e de toda uma economia globalizada, além da pressão pela responsabilidade quanto aos impactos negativos gerados ao meio ambiente a partir de suas operações e com a ascensão do ambientalismo internacional de consumo, envidaram esforços para que políticas voltadas para o desenvolvimento sustentável emergissem. Nesse sentido, Porter (1989) destacou a necessidade do entendimento de um contexto de globalização da competição, de modo que as empresas nacionais ao obterem vantagem competitiva, se insiram num contexto internacional e repassem tal vantagem para sua nação.
Alguns estudos têm abordado essa relação entre a competitividade e os aspectos verdes de empresas e governos. Lustosa (2011) afirmou que o grau de competição do mercado no qual a empresa está inserida é um dos fatores que mais influencia a decisão de gerar e adotar inovações, inclusive as ambientais. Segundo o autor a pressão dos mercados, sobretudo os mais competitivos, a inovação passa a ser fator de diferenciação entre a empresa e seus concorrentes, criando assimetrias entre elas e podendo ser a única forma de sobrevivência num mercado que valoriza a não agressão ao meio ambiente. Apak e Atay (2015) concluíram em sua pesquisa que a inovação verde e as tecnologias são consideradas como etapas importantes para as empresas que buscam ganhar competitividade internacional nos mercados globais. Borsatto e Amui (2019) identificaram uma relação negativa entre a competitividade dos países com as práticas de inovação verde de empresas de PD e PED.

Diante disso, e em busca de alcançar os objetivos do desenvolvimento econômico sustentável, muitos países têm buscado políticas ambientais mais rígidas, principalmente os países em desenvolvimento que tiveram nos últimos anos um crescimento econômico mais acelerado e se tornaram mais competitivos. Entretanto apesar desse crescimento, as diferenças nos níveis de desenvolvimento econômico e de sistemas políticos com os países desenvolvidos, torna-se limitado a aplicação de regulamentos ambientais mais rigorosos que podem auxiliar na manutenção do padrão de crescimento sustentável. (LIU et al., 2021).

Apesar dessa limitação, alguns estudos vêm demonstrando que o aumento do rigor das regulamentações ambientais melhora a capacidade e a estrutura da produção industrial (Yu; Shen, 2020; Zhang et al., 2020). E outros verificaram que independentemente do nível de desenvolvimento econômico, as políticas e arranjos institucionais tem papel fundamental na obtenção do crescimento verde (Reilly, 2012; Scoones et al., 2015).

Em relação à competitividade, Constantini e Mazzanti (2012) exploraram como a competitividade das exportações da União Europeia tem sido afetada pela regulamentação ambiental e inovação. E Herciu e Ogrean (2014) verificaram que a busca por um modelo que equilibre a prosperidade econômica, as questões ambientais e a sustentabilidade social 
demandam o que pode ser denominado "competitividade sustentável".

Nesse contexto, e considerando a importância das regulamentações ambientais para o desenvolvimento econômico sustentável e a melhoria da competitividade para as empresas e países tanto no contexto de economias emergentes e desenvolvidas, a presente pesquisa busca responder a seguinte questão: Existe alguma associação entre o rigor das regulamentações ambientais e a competitividade dos países Brasil e França?

Destarte, o objetivo principal deste estudo é verificar se existe algum tipo de associação entre o rigor das regulamentações ambientais e a competitividade dos países Brasil e França, entre 2005 e 2015, com base nos resultados dos indicadores de rigor das regulamentações ambientais Environmental Policy Stringency Index (EPS) da Organisation for Economic Cooperation and Development (OECD) e de competitividade Global Competitiveness Index (GCI) do World Economic Forum (WEF).

Justifica-se a escolha dos países Brasil e França por se tratar de países em desenvolvimento e desenvolvido, respectivamente, e que compõem o Grupo dos 20 (G20), das 20 maiores economias mundiais e apresentam situações distintas no que se refere a regulamentações ambientais e a competitividade. Essa comparação se torna relevante pois já se sabe que o crescimento industrial é um fator que promove além do desenvolvimento econômico e a competitividade dos países, geram impactos negativos no meio ambiente os quais podem ser minimizados pelo rigor das regulamentações ambientais.

\section{FUNDAMENTAÇÃO TEÓRICA}

\subsection{Regulamentações Ambientais: Environmental Policy Stringency Index}

A crescente preocupação com a relação entre crescimento econômico e questões ambientais tem impulsionado os países a elaborarem e adotarem políticas mais rígidas para o controle de suas ações nesse contexto, decorrente, principalmente, da conscientização ambiental quanto à escassez de recursos e degradação do meio ambiente.
Nesse cenário, as regulamentações ambientais emergem como forma de definir regras e incentivos a serem utilizados pelos países no intuito de minimizarem os impactos causados ao meio ambiente. A regulamentação ambiental pode ser definida como uma ferramenta tradicional para a solução dos problemas ambientais que decorre do efeito de pressão das políticas governamentais (CLEFF; RENNINGS, 1999; FRONDEL et al., 2007). Jaffe et al., (2005) consideram que a regulamentação ambiental é decorrente da necessidade de resposta à influência ambiental.

De acordo com a OECD (2018), as políticas ambientais contribuem para a sustentabilidade a longo prazo do crescimento ao se esforçarem para atingir os objetivos ambientais, podendo o rigor ser definido como custo implícito ou explícito do comportamento prejudicial ao meio ambiente. Em linhas gerais, a regulamentação ambiental pode ser classificada em dois tipos de instrumentos: instrumentos de comando e controle (CEC) e instrumentos baseados no mercado.

Os instrumentos de CEC referem-se às normas, regras, leis e padrões a serem seguidos pelos agentes econômicos, acompanhados de um conjunto de penalidades previstas, sendo os principais tipos: licenças, zoneamento e padrões. Os instrumentos baseados no mercado são aqueles que buscam incentivar os poluidores a reduzirem as emissões poluidoras, isto é, são incentivos econômicos complementares aos instrumentos de CEC, podendo ser: taxas ambientais, criação de um mercado, sistema de depósito e reembolso e subsídios (MARGULIS, 1998; REN et al., 2018).

Margulis (1998) assevera que existem outras iniciativas com o intuito de obrigarem os poluidores a controlarem suas emissões, sendo as principais: educação e informação, negociação direta e acordo voluntário, informação ao público e privatização e legislação de responsabilidade. Ren et al. (2018) incluem, ainda, os instrumentos denominados de regulamentação voluntária, que podem ser dispositivos de informação, acordos voluntários e participação do cidadão. Segundo os referidos autores, os instrumentos de regulamentação voluntária também fornecem incentivos, contudo, não determinam o controle da poluição.

Zhao, Yin e Zhao (2015) investigaram os impactos de três diferentes regulamentações ambientais na melhoria da eficiência e redução de $\mathrm{CO}_{2}$ na China. Os 
autores constataram que a regulamentação ambiental por meio de instrumentos baseados no mercado e subsídios do governo têm impacto positivo na melhoria da eficiência e redução de $\mathrm{CO}_{2}$, contudo, a regulamentação ambiental por meio de instrumentos de CEC não têm impactos significativos.

Kemp e Pontoglio (2011) examinaram os resultados de quatro literaturas acerca dos efeitos de inovação dos instrumentos de política ambiental. Dentre os achados, os autores constataram que as especificidades da política e a situação na qual elas são aplicadas são muito importantes para os resultados e que a influência de instrumentos baseados no mercado na inovação é muito mais fraca do que se supõe.

Além dessas abordagens sobre os tipos de regulamentações ambientais, estudos relacionando o seu impacto na produção industrial das empresas e no desenvolvimento regional estão sendo produzidos. Yu \& Shen (2020) verificaram que o aumento na intensidade da regulamentação ambiental pode melhorar significativamente a taxa de utilização da capacidade de produção industrial. Zhang et al. (2020) descobriram que as leis e regulamentações ambientais têm um impacto direto e indireto na atualização da estrutura industrial no desenvolvimento regional. Já Liu et al (2021) verificou que, em países em desenvolvimento, as diferenças nos níveis de desenvolvimento econômico e de sistemas políticos em relação aos países desenvolvidos, torna um fator limitante na implantação de regulamentos ambientais mais rigorosos que podem auxiliar a manutenção do padrão de crescimento sustentável.

Um dos esforços iniciais para a mensuração do rigor das políticas ambientais internacionalmente consiste no índice Environmental Policy Stringency (EPS). O EPS é divulgado pela OECD desde 1990, onde dados acerca das políticas ambientais dos países foram coletados a fim de criar uma proxy de rigor na política ambiental e verificar seus efeitos no desempenho econômico. $\mathrm{O}$ índice, portanto, apresenta quantitativamente o rigor das políticas ambientais dos países, agregando informações sobre instrumentos selecionados de política ambiental (OECD, 2018).

O índice EPS é composto por políticas baseadas no mercado e políticas não baseadas no mercado e abrange impostos relacionados ao meio ambiente, energia renovável e eficiência energética, padrões de desempenho e informações sobre depósitos e esquemas de reembolso. Atualmente o indicador concentra-se principalmente nas políticas relacionadas ao ar e ao clima, e é pontuado numa escala que varia de 0 a 6 , onde 6 representa políticas mais rigorosas (OECD, 2018).

\subsection{Competitividade: Global Competitiveness Index}

A inquietação por parte dos países em se manterem economicamente e globalmente competitivos no mercado é decorrente das contínuas mudanças com a globalização a partir do Século XXI. Se, durante décadas a partir da Revolução Industrial, o entendimento era de que o desenvolvimento econômico proporcionaria melhor qualidade de vida para a sociedade, a compreensão atual já é diferente.

O crescimento desordenado dos centros urbanos trouxe consigo os impactos negativos ao meio ambiente, e as questões ambientais passaram a ter destaque nas discussões. Segundo Donaire (1995, p. 11) esse novo paradigma é fruto da "reviravolta nos modos de pensar e agir, proporcionado pelo crescimento da consciência ecológica, na sociedade, no governo e nas próprias empresas que passaram a incorporar essa orientação em suas estratégias".

Constantini e Mazzanti (2012) afirmam que competitividade e produtividade são fatores-chave para desenvolvimento econômico e obtenção da sustentabilidade ambiental. A literatura considera a vantagem competitiva como um componente estratégico. O primeiro conceito de vantagem competitiva originou-se do entendimento de Ansoff (1965), que argumentou como sendo um atributo decorrente da "posição concorrencial". Contudo, somente a partir da década de 1980 que passou a ter destaque, com base nos estudos de Porter $(1985,1989)$. Para o autor, a obtenção de vantagem competitiva é fundamental para o sucesso no mercado.

A competitividade passou da análise das empresas para os países e, juntamente do crescimento econômico, pode ser considerada como um fator essencial para criação de bem-estar das nações (AIGINGER, 2006; BALKYTE; TVARONAVICIENE, 2011). Porter (1991) assegura que políticas ambientais podem promover a competitividade internacional. 
A OECD (2018) acredita que o rigor das políticas ambientais tenha efeitos sobre a atividade econômica, como, por exemplo, competitividade e inovação.

Porter (1991) e Porter e van der Linde (1995) argumentam que a regulamentação ambiental bem elaborada e aplicada beneficia tanto empresa, quanto o ambiente. Zhao, Yin e Zhao (2015) ao analisarem o impacto de diferentes regulamentações ambientais nas empresas chinesas, constaram que tais regulamentações promovem mudança de comportamento das empresas aumentando sua competitividade.

Constantini e Mazzanti (2012) objetivaram explorar como a competitividade das exportações da União Europeia tem sido afetada pela regulamentação ambiental e inovação. Partindo da Hipótese de Porter de que políticas ambientais podem fomentar a competitividade internacional, os autores constataram que no período analisado, entre 1996 e 2007, as ações de política ambiental parecem fomentar a dinâmica das exportações. Ademais, destacaram que globalmente, o cenário se apresenta largamente favorável aos efeitos positivos das políticas ambientais na competitividade. Do mesmo modo, à luz da Hipótese de Porter, Rubashkina et al., (2015), após analisarem dezessete países europeus no período de 1997 a 2009, verificaram evidências do impacto positivo da regulamentação ambiental em setores industriais europeus.

Ressalta-se que na presente pesquisa, para análise da competitividade dos países, adotou-se o índice Global Competitiveness Index (GCI). O GCI é um índice divulgado anualmente pelo World Economic Forum (WEF), que desde 2004 passou a classificar os países com base em sua competitividade. Para a composição do índice, fatores e instituições são identificados por meio de pesquisas empírica e teórica e avaliados como determinantes do nível de produtividade de um país. O Fórum Econômico Mundial (2018) considera que a produtividade é o principal determinante do crescimento a longo prazo e fator essencial no crescimento econômico e prosperidade de um país.

O índice é pautado em doze pilares que são agrupados dentro de três principais categorias, sendo que cada pilar é pontuado considerando uma escala de 1 (pior) a 7 (melhor) (Quadro 1). Para o cômputo final do GCI, é realizada uma média ponderada da pontuação desses pilares, considerando-se, ainda, o estágio de desenvolvimento do país, que é baseado em seu Produto Interno Bruto (PIB).

Quadro 1 Composição GCl

\begin{tabular}{l|l|l|l}
\hline \multicolumn{5}{c}{ Global Competitiveness Index } \\
\hline \multirow{2}{*}{ Categorias } & \multicolumn{1}{|c|}{ Requisitos Básicos } & \multicolumn{1}{|c}{ Potenciadores de Eficiência } & Fatores de Inovação e Sofisticação \\
\hline \multirow{2}{*}{ Pilares } & 1: Instituições & 5: Ensino Superior e Formação & 11: Sofisticação da produção \\
\cline { 2 - 4 } & 2: Infraestrutura & 6: Eficiência dos Mercados de Bens & 12: Inovação \\
\cline { 2 - 4 } & 3: Ambiente Macroeconômico & 7: Eficiência dos Mercados de Trabalho & \\
\cline { 2 - 4 } & 4: Saúde e Educação Primária & 8: Desenvolvimento do Mercado Financeiro & \\
\cline { 2 - 4 } & & 9: Disponibilidade Tecnológica & \\
\cline { 2 - 4 } & & 10: Dimensão do Mercado & \\
\hline
\end{tabular}

Fonte: WEF (2018).

Lima et al. (2017) fizeram uso do índice GCI para investigar a influência do desenvolvimento sustentável entre os países. Para análise, os autores adotaram, ainda, o Índice de Performance Ambiental (EPI - Environmental Performance Index) e Objetivos do Desenvolvimento Sustentável (SDG - Sustainable Development Goals). Os resultados apontam para im- pacto positivo na competitividade pelos indicadores, existindo uma correlação positiva entre desempenho ambiental e competitividade.

Herciu e Ogrean (2014) refletem que a busca por um modelo que equilibre a prosperidade econômica, as questões ambientais e a sustentabilidade social demandam o que pode ser denominado "competiti- 
vidade sustentável”. Balkyte e Tvaronavičiene (2011) afirmam que a competitividade deve ser sustentada por uma visão ampla de economia e sociedade, numa relação significativa entre desenvolvimento sustentável e competitividade.

\section{ASPECTOS METODOLÓGICOS}

Como o objetivo do estudo é verificar se existe algum tipo de associação entre o rigor das regulamentações ambientais e a competitividade dos países Brasil e França, entre 2005 e 2015, com base nos resultados dos indicadores de rigor das regulamentações ambientais e de competitividade, o presente estudo caracteriza-se por ser uma pesquisa descritiva com abordagem quali-quantitativa, dado que coexiste a interpretação qualitativa e quantitativa dos dados.

Para a análise empregou-se o teste estatístico correlação linear de Pearson para verificar se existe algum tipo de associação entre o rigor das regulamentações ambientais e a competitividade dos países Brasil e França. Essa técnica permite verificar a força de correlação entre duas variáveis analisadas a partir de seus resultados que variam de -1 a 1 (FAVERO \& VELFIORI, 2017).

Além disso, por meio da correlação é possível apenas fazer afirmações sobre associações e não sobre causa e efeito, a partir do comportamento linear entre duas variáveis quantitativas, indicando direção e magnitude dessa associação (DRAPER; SMITH, 1998). Autores como Silveira e Oliveira (2013) e Suchek et al (2020) também fizeram uso da técnica para análise de associações entre variáveis.

Para a análise destaca-se que, ao nível de 5\% de significância, as pressuposições de normalidade foram verificadas e comprovadas por meio dos testes de Shapiro-Wilk. Estas análises foram realizadas no software STATA.

Justifica-se a escolha dos países Brasil e França por se tratar de países em desenvolvimento e desenvolvido, respectivamente, e que compõem o Grupo dos 20 (G20), das 20 maiores economias mundiais e apresentam situações distintas no que se refere a regulamentações ambientais e a competitividade. $\mathrm{O}$ G20 foi criado em 1999 e é constituído por países que visam discutir questões relativas à economia global, incluindo o desenvolvimento sustentável. Outrossim, o G20 consiste num grupo de países de grande representatividade no cenário mundial, respondendo por $90 \%$ do PIB mundial, além de $80 \%$ do comércio mundial, dois terços da população mundial e $84 \%$ da emissão de gases de efeito estufa (ITAMARATY, 2018).

Para atender aos objetivos específicos desse estudo, a pesquisa qualitativa foi aplicada com uma análise descritiva acerca do comportamento das variáveis evolução do rigor das regulamentações ambientais e nível de competitividade, com foco nas experiências e especificidades individuais dos países Brasil e França entre o período de 2005 e 2015.

Os dados dos indicadores relacionados ao rigor das políticas ambientais dos países são provenientes da $O E C D$ e são pontuados numa escala de 0 a 6 , onde 6 denota políticas mais rigorosas. Já os dados dos indicadores relativos à competitividade dos países são originários do WEF que, inclusive, apresenta anualmente o relatório de competitividade global onde divulga um ranking dos países no que tange à competitividade, sendo que esses indicadores são apresentados numa escala de 0 a 7 , sendo pior desempenho e melhor desempenho, respectivamente.

Ressalta-se que a análise se circunscreve ao corte temporal de 2005 a 2015 em decorrência da disponibilidade da base de dados referente ao Índice de Rigor das Políticas Ambientais da OECD.

\section{APRESENTAÇÃO E DISCUSSÃO DOS RESULTADOS}

\subsection{Análise do Rigor das Regulamentações Ambientais e da Competitividade}

Primeiramente analisou-se comparativamente a evolução dos indicadores do rigor das regulamentações ambientais e da competitividade do Brasil (País em Desenvolvimento - PED) e da França (País Desenvolvido - PD), buscando identificar as características das regulamentações e da competitividade destes países.

A partir dos dados, verificou-se que a França, no período analisado, é um país com maior rigor em 
suas políticas ambientais, apresentando em média um índice de 3,377, destacando dois períodos (2009 e 2011) onde os indicadores apresentaram um aumento significativo que se manteve até 2015 , fim do período analisado, conforme apresentado na Figura 1. Este fato pode estar relacionado com a evolução das políticas ambientais no país.

Até 2005, apesar das políticas ambientais serem um fator relevante para toda a União Europeia, a França não apresentava políticas ambientais que tratavam o problema com profundidade. Foi a partir da consolidação da Carta ao Meio Ambiente (código ambiental francês), através da lei n 2005-205 de $01 / 03 / 2005$, e do desenvolvimento do programa chamado de Lei Grenelle Environment em 2007 que o Estado juntamente com representantes da sociedade civil e Organizações não Governamentais (ONGs) se uniram em favor do desenvolvimento sustentável e na luta contra as mudanças climáticas (IAMAGUCHI; MARTINS DE SOUZA, 2011). Como o índice que mede o rigor das regulamentações ambientais dos países concentram-se principalmente nas políticas

Figura 1 Evolução dos índices EPS e GCl - França e Brasil

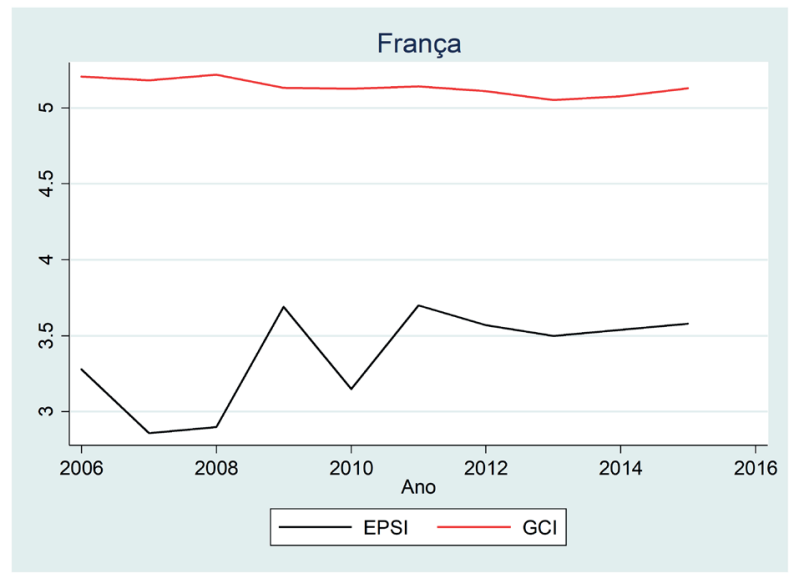

Fonte: Dados da pesquisa.

A competitividade é definida pelo WEF (2016) como um conjunto de instituições, políticas e fatores que determinam o nível de produtividade de um país. O GCI através dos 12 pilares verifica a evolução da competitividade dos países a partir dos efeitos das políticas públicas e das ações das empresas. A OECD (2018) acredita que o rigor das políticas ambientais tenha efeitos sobre a atividade econômica, como a competitividade e inovação. relacionadas ao ar e ao clima, essas mudanças nas políticas públicas na França podem estar refletindo nos seus resultados.

Já o Brasil apresentou pouca evolução no rigor de suas políticas ambientais, conforme demonstrado na Figura1. O país apresentou um índice em média de 0,418 , bem inferior ao da França, demonstrando uma baixa severidade nas suas políticas ambientais. Apesar da promulgação da política ambiental do país na Constituição Federal de 1988, e de ser considerada uma das leis ambientais mais avançadas do mundo, isso não se reflete no rigor das regulamentações medidas pela $O E C D$. Apesar de ser uma lei rigorosa, ela é questionada acerca de sua aplicação, uma vez que muitos crimes acabam sem punição. E como o índice é composto por políticas baseadas no mercado e não baseadas no mercado, e abrange impostos relacionados ao meio ambiente, energia renovável, eficiência energética e padrões de desempenho, se a lei não estiver sendo aplicada e os transgressores punidos, isso não reflete no seu rigor.

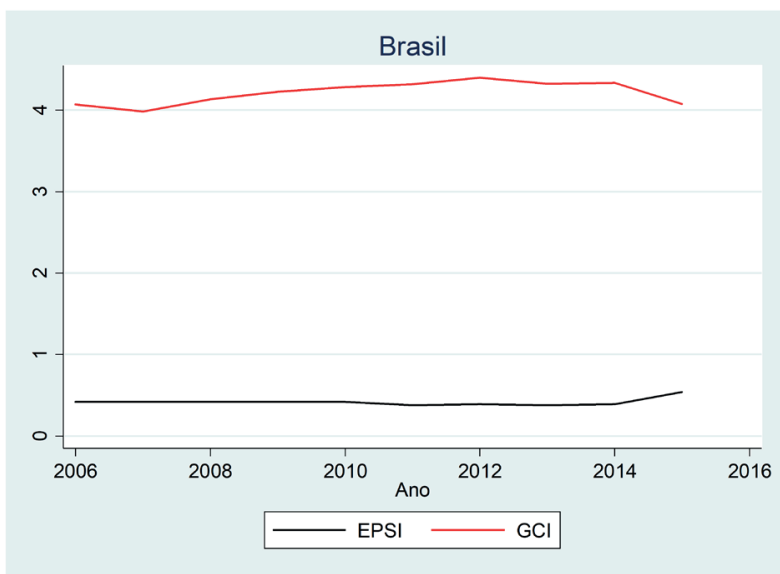

Diante disso, foi relevante analisar a evolução do índice de competitividade global (GCI) da França e do Brasil. Verificou-se que a França manteve em média um índice de competitividade de 5,1369 no período de 2005-2015, sendo os pilares básicos de Infraestrutura e de Saúde e Educação primária os de maior valor. Já no Brasil, o índice de competitividade global apresentou em média um valor de 4,2169, sendo os principais pilares que contribuíram foram 
Saúde e Educação primária e o pilar de Dimensão do mercado. Entretanto verifica-se que o país recuou no índice de competitividade nos anos de 2014 e 2015, fato este que pode ser justificado pela instabilidade macroeconômica e a perda da confiança nas instituições públicas devido ao cenário político no período.

\subsection{Correlação entre Rigor das Regulamentações Ambientais e da Competitividade}

Para verificar se existe algum tipo de associação entre o rigor das regulamentações ambientais e a competitividade dos países Brasil e França aplicou-se o teste de correlação linear de Pearson e foi possível verificar a existência de associação entre alguns indicadores tanto do Brasil como da França, conforme Tabela 2. Ressalta-se ainda que ao nível de significância de $5 \%$ o pressuposto da normalidade bivariada, por meio do teste de Shapiro-Wilk foi comprovada.

Em relação ao Brasil, a partir dos resultados da correlação constatou-se que, ao nível de significância de $5 \%$, embora os resultados não sejam estatisticamente significativos para a maioria dos indicadores, verificou-se uma correlação negativa de moderada a forte entre o rigor das regulamentações ambientais e a maioria dos indicadores de competitividade analisados. Somente os pilares 9 (Disponibilidade Tecnológica) e o 10 (Dimensão do mercado) que apresentaram uma correlação positiva de 0,1214 e 0,4549, respectivamente, porém sem significância estatística.

Além disso, constatou-se também que a severidade das regulamentações ambientais possui uma correlação negativa e significante estatisticamente com os pilares das Instituições, que envolve aspectos como propriedade de direitos, ética pública e privada, segurança, do Desenvolvimento do Mercado Financeiro, que abrange questões de confiança no mercado e da Sofisticação da Produção. Esses resultados do Brasil não corroboram com os estudos de Porter (1991) e de Zhao, Yin e Zhao (2015) que afirmam que as regulamentações podem promover uma maior competitividade nas empresas e uma maior competitividade internacional.

Quanto à França, os resultados demonstram que o rigor das regulamentações ambientais possui uma correlação negativa e significante estatisticamente
Tabela 2 Correlação Rigor das Políticas Ambientais e Competitividade

\begin{tabular}{c|c|c|c|c}
\hline \multirow{2}{*}{ Variáveis } & \multicolumn{2}{|c|}{ Brasil } & \multicolumn{2}{c}{ França } \\
\cline { 2 - 5 } & r & p-value & R & p-value \\
\hline P1 & $-0,588$ & 0,073 & $-0,634$ & 0,049 \\
\hline P2 & $-0,740$ & 0,014 & $-0,654$ & 0,040 \\
\hline P3 & $-0,879$ & 0,809 & $-0,462$ & 0,178 \\
\hline$P 4$ & $-0,411$ & 0,237 & $-0,824$ & 0,003 \\
\hline$P 5$ & $-0,609$ & 0,061 & $-0,576$ & 0,081 \\
\hline$P 6$ & $-0,546$ & 0,102 & $-0,669$ & 0,034 \\
\hline P7 & $-0,623$ & 0,053 & 0,689 & 0,027 \\
\hline$P 8$ & $-0,657$ & 0,038 & $-0,634$ & 0,048 \\
\hline$P 9$ & 0,121 & 0,738 & 0,687 & 0,028 \\
\hline$P 10$ & 0,454 & 0,186 & 0,571 & 0,084 \\
\hline$P 11$ & -0682 & 0,029 & $-0,695$ & 0,025 \\
\hline P12 & $-0,608$ & 0,062 & 0,218 & 0,543 \\
\hline
\end{tabular}

Fonte: Dados da pesquisa.

Nota: GCl - Índice de Competitividade Global; P1 - Pilar 1 (Instituições); P2 - Pilar 2(Infraestrutura); P3 - Pilar 3(Ambiente Macroeconômico; P4 - Pilar 4(Saúde e Educação Primária); P5 - Pilar 5(Ensino Superior e Formação); P6 - Pilar 6(Eficiência dos Mercados de Bens); P7 - Pilar 7(Eficiência do Mercado de Trabalho); P8 - Pilar 8(Desenvolvimento do Mercado Financeiro); P9 - Pilar 9(Disponibilidade Tecnológica); P10 - Pilar 10(Dimensão do mercado); P11 - Pilar 11 (Sofisticação da produção); P12 - Pilar 12(Inovação).

com os indicadores Instituições, Ambiente Macroeconômico, Eficiência dos Mercados de Bens, Desenvolvimento do Mercado Financeiro, Sofisticação da Produção e com o Índice de Competitividade Global. E possui uma correlação positiva e significante estatisticamente com a Eficiência do Mercado de Trabalho e com a Disponibilidade Tecnológica. Esses resultados constatam que um maior rigor das regulamentações tem associação com a competitividade dos países tanto nos requisitos básicos como nos potenciadores de eficiência e de inovação refletindo na competitividade global do país.

Constantini e Mazzanti (2012) e Rubashkina, Galeotti e Verdolini (2015) analisaram países europeus e identificaram que existe relação entre regulamentações ambientais e competitividade relacionando a exportações e setores industriais, com isso pode-se afirmar que os resultados da França corroboram com 
os autores, pois confirmam a existência de relação entre as variáveis sendo elas positivas e negativas.

A partir da comparação dos resultados, verificaram-se divergências tanto no rigor das regulamentações ambientais como na formação da competitividade dos dois países, o que pode ser explicado pelo fato de se tratar de um país desenvolvido e de um país em desenvolvimento. Verificou-se que a França, um país desenvolvido, possui políticas ambientais mais rigorosas e é um país mais competitivo quando comparado ao Brasil, um país em desenvolvimento. Além disso, quando se analisa a associação das regulamentações ambientais com a competitividade, constata-se que em uma economia mais desenvolvida a preocupação em preservar o meio ambiente tem associações mais significativas com os pilares que formam a competitividade de um país.

\section{CONSIDERAÇÕES FINAIS}

Este estudo buscou verificar se existe algum tipo de associação entre o rigor das regulamentações ambientais e a competitividade dos países Brasil e França, entre os anos de 2005 e 2015. Para atingir este objetivo, primeiramente analisou-se a evolução dos indicadores do rigor das regulamentações ambientais da $O E C D$ e dos indicadores de competitividade do WEF de ambos os países. A partir dos resultados verificou-se que a França é um país com maior rigor em suas políticas ambientais, apesar de não estar garantido na Constituição do país, a Carta ao Meio Ambiente através da lei n 2005-205 de 01/03/2005, e do desenvolvimento do programa chamado de Lei Grenelle Environment em 2007, criou um comprometimento do Estado, da sociedade e ONGs em favor do desenvolvimento sustentável. Já no Brasil, apesar da política ambiental estar promulgada na Constituição Federal de 1988, e de ser considerada uma das leis ambientais mais avançadas do mundo, isso não se reflete no rigor das regulamentações medidas pela OECD.

Em relação à associação entre o rigor das regulamentações ambientais e a competitividade dos países, os resultados de teste de correlação de Pearson, verificou-se que no Brasil, as regulamentações ambientais apresentaram uma correlação negativa e estatisticamente significante somente com os pilares das Instituições, que envolve aspectos como propriedade de direitos, ética pública e privada, segurança, do Desenvolvimento do Mercado Financeiro, que envolve questões de confiança no mercado e da Sofisticação da Produção, não corroborando com os estudos de Porter (1991) e de Zhao, Yin e Zhao (2015).

Já na França, os resultados demonstraram que o rigor das regulamentações ambientais possui uma correlação negativa e significante estatisticamente com os indicadores Instituições, Ambiente Macroeconômico, Eficiência dos Mercados de Bens, Sofisticação da Produção e com o Índice de Competitividade Global. E possui uma correlação positiva e significante estatisticamente com a Eficiência do Mercado de Trabalho e com a Disponibilidade Tecnológica. Estes resultados corroboram com os estudos de Constantini e Mazzanti (2012) e de Rubashkina et al (2015) por confirmar a existência de relação entre as variáveis sendo elas tanto positivas como negativas.

Quando comparado os dois países verificou-se uma divergência nos resultados podendo ser justificada por se tratar de um país desenvolvido e um país em desenvolvimento que apresentam níveis de desenvolvimento econômico e sistemas políticos distintos. Esses fatores segundo Liu et al (2021) podem ser um limitador a implantação de políticas ambientais mais rigorosas que impactam positivamente a capacidade e a estrutura industrial das empresas e que podem melhorar o desempenho e o crescimento verde de uma região tornando-a mais competitiva.

Diante disso, este trabalho alcançou o objetivo proposto verificando a associação entre o rigor das regulamentações ambientais e da competitividade do Brasil e da França, destacando que a França apresentou um rigor maior em suas políticas ambientais que o Brasil, e também demonstrou um maior grau de competitividade. Além disso, as regulamentações ambientais no Brasil estavam correlacionadas negativamente somente com três pilares da competitividade, enquanto a França apresentou correlação com oito pilares da competitividade.

Desta forma, esse trabalho contribui com a literatura demonstrando a importância do rigor das regulamentações ambientais para a melhoria no desempenho da produção industrial verde que promove o desenvolvimento econômico sustentável e melhora 
a competitividade a longo prazo tanto em economias emergentes como em economias desenvolvidas.

Os resultados do Brasil, um país em desenvolvimento, apresentou divergências na literatura, demonstrando uma necessidade de futuros estudos buscando a comparação entre países desenvolvidos e países em desenvolvimento utilizando outras variáveis para mensurar tanto as regulamentações ambientais como a competitividade. Apesar disso, considera-se uma limitação do estudo a análise apenas de um índice para mensurar o rigor das regulamentações ambientais, haja vista existirem outras formas que podem avaliar as políticas ambientais dos países.

\section{REFERÊNCIAS}

AIGINGER, K. T. Competitiveness: From a Dangerous Obsession to a Welfare Creating Ability with Positive Externalities. Journal of Industry, Competition and Trade, v. 6, n. 2, p. 161-177, jun. 2006.

ANSOFF, H. I. Corporate strategy. Harmondsworth: Penguin. 1965.

APAK, Sudi; ATAY, Erhan. Global competitiveness in the EU through green innovation technologies and knowledge production. Procedia-Social and Behavioral Sciences, v. 181, p. 207-217, 2015.

BALKYTE, A.; TVARONAVICIENE, M. Perception of competitiveness in the context of sustainable development: Facets of sustainable competitiveness. Journal of Business Economics and Management, v. 11, n. 2, p. 341-365, jun. 2011.

BRASIL. Ministério das Relações Exteriores. O Brasil no G-20. 2018. Disponível em: <http://www.itamaraty.gov.br/pt-BR/politica-externa/diplomacia-economica-comercial-e-financeira/15586-brasil-g20>. Acesso em: 25 out. 2018.

BORSATTO, Jaluza Maria Lima Silva; AMUI, Lara Bartocci Liboni. Green innovation: Unfolding the relation with environmental regulations and competitiveness. Resources, Conservation and Recycling, v. 149, p. 445-454, 2019.
CLEFF, T.; RENNINGS, K. Determinants of environmental product and process innovation. European environment, v. 9, n. 5, p. 191-201, 1999.

CONSTANTINI, V.; MAZZANTI, M. On the green and innovative side of trade competitiveness? The impact of environmental policies and innovation on EU exports. Research Policy, v. 41, n.1, p. 132-153, fev. 2012.

COSTA, R. S.; MARION, J. C. A Uniformidade na Evidenciação das Informações Ambientais. Revista Contabilidade \& Finanças, n. 43, p. 20-33, jan./abr. 2007.

DONAIRE, D. Gestão Ambiental na empresa. São Paulo: Atlas, 1995.

DRAPER, N. R.; SMITH, H. Applied regression analysis. 3. ed. New York: John Wiley e Sons, 1998.

FÁVERO, Luiz Paulo; BELFIORE, Patrícia. Manual de análise de dados: estatística e modelagem multivariada com Excel $^{\oplus}$, SPSS $^{\oplus}$ e Stata $^{\circledR}$. Elsevier Brasil, 2017.

FÓRUM ECONÔMICO MUNDIAL - FEM. The Global Competitiveness Report. 2018. Disponível em: <http://www3.weforum.org/docs/GCR20172018/05FullReport/TheGlobalCompetitiveness Report2017\%E2\%80\%932018.pdf>. Acesso em: 03 nov. 2018.

FRONDEL, M.; HORBACH, J.; RENNINGS, K. End of pipe or cleaner production? An empirical comparison of environmental innovation decisions across OECD countries. Business strategy and the environment, v. 16, n. 8, p. 571-584, 2007.

HERCIU, M.; OGREAN, C. An Overview on European Union Sustainable Competitiveness. Procedia Economics and Finance, v. 16, p. 651-656, 2014. 
IAMAGUCHI, T. E.; MARTINS DE SOUZA, M. C. França: A construção do direito ambiental em um país desenvolvido. Revista Tópos. v. 5, n. 2, p. 47-66, 2011.

JAFFE, A. B.; NEWELL, R. G.; STAVINS, R. N. A tale of two market failures: technology and environmental policy. Ecological Economics, v. 54, n. 2-3, p. 164174, ago. 2005.

KEMP, R.; PONTOGLIO, S. The innovation effects of environmental policy instruments - A typical case of the blind men and the elephant? Ecological Economics, v. 72, p. 28-36, dez. 2011.

LIMA, M. L. B.; FROTA, J. A.; ARAÚJO, F. S. M.; FONTENELE, R. E. S. Desenvolvimento sustentável e competitividade nas nações: uma análise multivariada. Reuna, v. 22, n. 1, p. 41-62, 2017.

LIU, Lijun et al. Are Environmental Regulations Holding Back Industrial Growth? Evidence from China. Journal of Cleaner Production, p. 127007, 2021.

LUSTOSA, MARIA CECÍlIA JUNQUEIRA. Inovação e tecnologia para uma economia verde: questões fundamentais. Política Ambiental, v. 8, p. 111-122, 2011.

MARGULIS, S. A regulamentação ambiental: instrumentos e implementação (Texto para discussão, N 437). Brasília, DF: IPEA, 1998.

\section{NAÇÕES UNIDAS. Adoção do Acordo de Paris.} 2015. Disponível em: <https://nacoesunidas.org/ wp-content/uploads/2016/04/Acordo-de-Paris.pdf $>$. Acesso em: nov. 2018.

PORTER, M. E. A vantagem competitiva das nações. Rio de Janeiro: Campus, 1989.

PORTER, M. E. America’s Green strategy. Scientific American, v. 264, n. 4, p. 168, abr. 1991.
PORTER, M. E. Competitive advantage: creating and sustaining superior performance. New York: The Free Press, 1985.

PORTER, M. E.; VAN DER LINDE, C. Toward a New Conception of the Environment-Competitiveness Relationship. Journal of Economic Perspectives, v. 9, n. 4, p. 97-118, 1995.

REN, S., LI, X., YUAN, B., LI, D. \& CHEN, X. The effects of three types of environmental regulation on ecoefficiency: A cross-region analysis in China. Journal of Cleaner Production, v. 173, p. 245-255, fev. 2018.

REILLY, John M. Green growth and the efficient use of natural resources. Energy Economics, v. 34, p. S85-S93, 2012.

RUBASHKINA, Y.; GALEOTTI, M.; VERDOLINI, E. Environmental regulation and competitiveness: Empirical evidence on the Porter Hypothesis from European manufacturing sectors. Energy Policy, v. 83, p. 288-300, ago. 2015.

SCOONES, Ian; LEACH, Melissa; NEWELL, Peter (Ed.). The politics of green transformations. Routledge, 2015.

SILVEIRA, Juliane Dias Coelho de Araújo; OLIVEIRA, Murilo Alvarenga. Inovação e desempenho organizacional: um estudo com empresas brasileiras inovadoras. Sociedade, Contabilidade e Gestão, v. 8, n. 2, 2013.

STAVINS, R. N. Correlated uncertainty and policy instrument choice. Journal of Environmental Economics and Management, v. 30, n. 2, p. 218-232, mar. 1996. 
SUCHEK, Nathalia; FERNANDES, Paula; NASCIMENTO, Thiago Cavalcante. Empreendedorismo e competitividade: Aplicação de uma análise de cluster. In: XXX Jornadas LusoEspanholas de Gestão Científica: cooperação transfronteiriça: desenvolvimento e coesão territorial: livro de resumos. Instituto Politécnico de Bragança, 2020. p. 125.

YU, Binbin; SHEN, Chen. Environmental regulation and industrial capacity utilization: An empirical study of China. Journal of Cleaner Production, v. 246, p. 118986, 2020.

ZHANG, Yixiang et al. Environmental regulation, capital output and energy efficiency in China: An empirical research based on integrated energy prices. Energy Policy, v. 146, p. 111826, 2020.

ZHANG, Ming; SUN, Xinran; WANG, Wenwen. Study on the effect of environmental regulations and industrial structure on haze pollution in China from the dual perspective of independence and linkage. Journal of Cleaner Production, v. 256, p. 120748, 2020.

ZHAO, X.; YIN, H.; ZHAO, Y. Impact of environmental regulations on the efficiency and $\mathrm{CO}_{2}$ emissions of power plants in China. Applied Energy, v. 149, p. 238-247, jul. 2015. 